\title{
Preparation and characterization of Ni-Zn ferrite + polymer nanocomposites using mechanical milling method
}

\author{
P. Raju $\cdot$ S. R. Murthy
}

Received: 1 September 2012/ Accepted: 28 September 2012/Published online: 16 October 2012

(C) The Author(s) 2012. This article is published with open access at Springerlink.com

\begin{abstract}
The insulating properties of Ni-Zn ferrites can be improved by the addition of various types of insulating materials such as polymers, ceramics, etc. In this connection, ferrite-polymer composites have been subjected to extensive research, because they have many applications: electromagnetic interference shielding, rechargeable battery, electrodes and sensors, and microwave absorption. Electrical and magnetic properties of such composites will depend on the size, shape and amount of filler addition. In this paper, we report the preparation and characterization of nanocomposites of $\mathrm{Ni}-\mathrm{Zn}$ ferrite + paraformaldehyde. These nanocomposites were prepared by using mechanical milling method and characterized by X-ray powder diffraction, scanning electron microscopy (SEM) and Fourier transform infrared spectrometer. The particle size estimated from SEM pictures for composites varies from 36 to $60 \mathrm{~nm}$. Magnetic properties were measured on nanocomposites at room temperature. The complex permittivity and permeability were measured over a wide frequency range from $1 \mathrm{MHz}$ to $1.8 \mathrm{GHz}$ at room temperature. From our studies, it is observed that both the values of permittivity and permeability decrease with an increase in polymer content.
\end{abstract}

Keywords Polymer nanocomposites - Ferrites · Mechanical milling · Dielectric properties · Magnetic properties

P. Raju ( $₫) \cdot$ S. R. Murthy

Department of Physics, Osmania University,

Hyderabad 500 007, India

e-mail: panthagani.raju@gmail.com

\section{Introduction}

Magnetic insulator-conducting polymer composites have attracted considerable attention for their potential applications in various fields such as electromagnetic interference (EMI) shielding, rechargeable battery, electrodes and sensors, and microwave absorption (Ahmad and MacDiarmid 1996; Mäkelä et al. 1997; Kuwabata et al. 1999; Kan et al. 2004). Inorganic-conducting polymer composites possess high mechanical strength and hardness of inorganic components and the nature of the flexibilities and process ability of polymers. Recently, many studies have focused on the inorganic-PANI composites (Danielle et al. 2003; Qiu and Gao 2005) to obtain materials with complementary behavior between polyaniline and inorganic materials. However, the mechanical properties of these composites are found to be low. In search of new ferrite-polymer nanocomposites with high mechanical strength, good environment stability and relatively easy preparation, we have undertaken this work.

Among the different spinel ferrites, NiZn ferrites are the most versatile magnetic materials for general use. They exhibit low magnetic coercivity and high electrical resistivity which greatly reduces eddy current losses at high frequencies, high Curie temperature, good mechanical hardness and chemical stability. Due to all these properties, NiZn ferrites have extensive applications such as in recording heads, antenna rods, loading coils, microwave devices and core materials for power transformers in electronics and telecommunication (Da Silva and Mohallem 2001; Costa et al. 2003; Jalaly et al. 2009; Sertkol et al. 2009). In this connection, few studies were carried out on $\mathrm{Ni}$ ferrites + polymer (Sohn et al. 1998; Chein 1995; Leslie-Pelecky and Rieke 1996; Shull et al. 1990) composites. It is interesting that the electrical and magnetic 
properties of NiZn ferrite + polymer composites can be tailored by controlling the preparation conditions and amount of metal ion substitution. At low frequencies, the electromagnetic waves can be effectively shielded by the magnetic source and the conducting polymer can effectively shield the electromagnetic waves generated from an electric source. Thus, the composite material having both magnetic and conducting components is used for EMI shielding applications.

The traditional methods for preparing composites involve conventional solid-state synthesis techniques, which are known to have serious limitations, such as chemical inhomogeneity, poor compositional control and the formation of large particles (Yang et al. 2003; Kazantseva et al. 2004; Yavuz et al. 2005). Several synthesis methods have been developed to prepare composites with nanoparticle size and homogeneity such as chemical co-precipitation, hydrothermal processing, sol-gel and mechanical alloying. The mechanical alloying technique, in addition to reducing grain size and mixing powders uniformly, has proved to be a powerful tool for the synthesis of various kinds of materials, such as amorphous alloys, nanocrystalline metals and alloys and ceramic materials (Giri 1997; Ambrose et al. 1992; Linderoth and Pedersen 1994; Giri et al. 1994). Hence, in the present investigation, NiZn ferrite (NZ) + paraformaldehyde (PFD) nanocomposites were prepared using the mechanical milling method. The prepared samples were characterized using X-ray powder diffraction (XRD), Fourier transform infrared spectrometer (FTIR) and scanning electron microscopy (SEM). The effect of the volume fraction of polymer on the frequency dispersion characteristics of the complex permittivity and permeability is studied.

\section{Experimental method}

For the synthesis of $\mathrm{Ni}_{0.5} \mathrm{Zn}_{0.5} \cdot \mathrm{Fe}_{2} \mathrm{O}_{4}$, pure nickel nitrate $\left[\mathrm{Ni}\left(\mathrm{NO}_{3}\right)_{2} \cdot 6 \mathrm{H}_{2} \mathrm{O}\right]$, zinc nitrate $\left[\mathrm{Zn}\left(\mathrm{NO}_{3}\right)_{2} \cdot 6 \mathrm{H}_{2} \mathrm{O}\right]$ and iron nitrate $\left[\mathrm{Fe}\left(\mathrm{NO}_{3}\right)_{2} \cdot 9 \mathrm{H}_{2} \mathrm{O}\right]$, all from Aldrich, were used as received without further purification. The required amounts were weighed and mixed accordingly in a vial to achieve the stoichiometry. Mechanical alloying was carried out in the hardened WC vial together with ten 12-mm WC balls for $12 \mathrm{~h}$ using a Retsch Co. high energy planetary ball mill. A ball to powder mass charge ratio of 14:1 was chosen. The speed of the mill was set at $400 \mathrm{rpm}$ with an interval of $40 \mathrm{~min}$. The total grinding time to prepare the ferrite powder was $40 \mathrm{~h}$. The 40 -h milled powder was sintered at $850{ }^{\circ} \mathrm{C} / 2 \mathrm{~h}$. The powders were characterized using X-ray diffractometer (XRD, PhilipsPW-1730 with $\mathrm{Cu}-\mathrm{K}_{\alpha}$ radiation and $\lambda=1.5406 \AA$ ) and transmission electron microscopy (TEM,model JEM-2010, JEOL, Tokyo, Japan).
The synthesized nanopowders of $\mathrm{Ni}_{0.5} \mathrm{Zn}_{0.5} \mathrm{Fe}_{2} \mathrm{O}_{4}$ and paraformaldehyde (PFD, Sigma-Aldrich, particle size $\leq 10 \mu \mathrm{m})$ were mixed at different weight percentages to obtain the composites of paraformaldehyde $(x)+(1-x)$ $\mathrm{Ni}_{0.5} \mathrm{Zn}_{0.5} \mathrm{Fe}_{2} \mathrm{O}_{4} \quad(0 \leq x \leq 1)$ and named as $\mathrm{Ni}_{0.5} \mathrm{Zn}_{0.5}$ $\mathrm{Fe}_{2} \mathrm{O}_{4}(\mathrm{NZ} 1), \quad 75 \mathrm{wt} \% \quad \mathrm{NiZn}$ ferrite $+25 \mathrm{wt} \%$ PFD (NZ2), 50 wt $\%$ NiZn ferrite $+50 \mathrm{wt} \% \operatorname{PFD}(\mathrm{NZ3})$ and $25 w t \%$ of NiZn ferrite $+75 w t \%$ PFD (NZ 4) paraformaldehyde (PFD). The mixed powders were milled in a mechanical mill for 10, 15, 20 and $40 \mathrm{~h}$ under air atmosphere. The ball-to-powder mass ratio and rotating speed were 14:1 and $400 \mathrm{rpm}$, respectively. 40-h milled samples were subjected to annealing at $150{ }^{\circ} \mathrm{C}$ for $10 \mathrm{~min}$. Then the samples were characterized by X-ray diffraction (XRD), scanning electron microscopy (SEM, LEICA, S440i, UK) and Fourier transform infrared spectrometer (FTIR, Brucker tensor 27). The crystallite size of the milled samples was calculated using Scherer equation (Zhao et al. 1997), based on the widening of three strongest peaks of a certain phase. The magnetic properties such as saturation magnetization $\left(\mathrm{M}_{\mathrm{s}}\right)$ and coercive field $\left(\mathrm{H}_{\mathrm{c}}\right)$ for the samples were obtained from the recorded hysteresis loops obtained with the help of Vibrating sample magnetometer (VSM, Model DMS 1660 model) at room temperature. The complex permittivity $\left(\varepsilon^{*}\right)$ and permeability $\left(\mu^{*}\right)$ were measured in the frequency range of $1 \mathrm{MHz}$ to $1.8 \mathrm{GHz}$ using impedance analyzer (HP 4291B) at room temperature.

\section{Results and discussions}

Figure 1 shows the XRD pattern for the as-synthesized powder of $\mathrm{Ni}_{0.5} \mathrm{Zn}_{0.5} \mathrm{Fe}_{2} \mathrm{O}_{4}(\mathrm{NZ} 1)$. The characteristic peak (311) of ferrite can be observed at $2 \theta=\sim 34^{\circ}$. It can be seen from the figure that all the main peaks are related to a single-phase spinel structure. No impurity phases were detected in the XRD patterns. The crystallite size $\left(D_{\mathrm{m}}\right)$ of the ferrite was calculated from the X-ray peak broadening of the (3 111 ) diffraction peak using Scherer's formula:

$D_{\mathrm{m}}=K \lambda / \beta \operatorname{Cos} \theta$

where $K$ is a constant, $\beta$ is the full width half maxima and $\lambda$ is the wavelength of $\mathrm{X}$-rays used and $\theta$ is the diffraction angle. The average crystallite size estimated for the NZ1 sample is $30 \mathrm{~nm}$. Figure 2 shows the TEM picture of assynthesized single-phase NiZn ferrite (NZ1) nanopowders and, as can be seen, there is a uniform distribution of particle size with mean particle size of $25 \mathrm{~nm}$, which is in agreement with Scherer's result.

Figure 1 also gives the XRD patterns for all the composites under investigation. The XRD pattern for the free polymer does not show any sharp peaks suggesting an amorphous nature of PFD. However, the polymer displays 


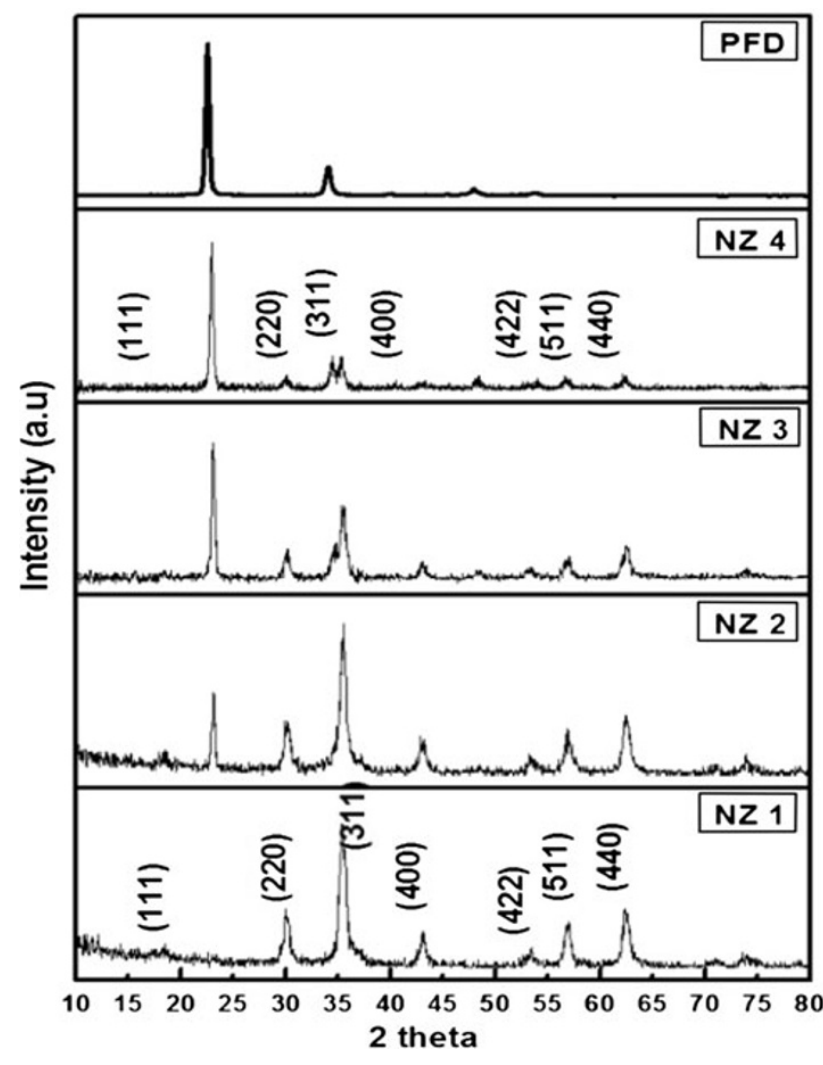

Fig. 1 XRD patterns of synthesized $x$ PZF $+(1-x)$ NZF nanocomposites $(0 \leq x \leq 1)$

a PFD characteristic peak at $30^{\circ}$. The XRD patterns for nanocomposites (NZ 2, NZ 3 and NZ 4) show crystalline peaks due to the presence of ferrite. The main characteristic peak of PFD disappeared because the ferrite nanoparticles interfered with the polymer chains. It can also be observed from the figures that the diffraction peaks were broadened initially for pure ferrite and became narrow with higher additions of polymer. The crystallite size $\left(D_{\mathrm{m}}\right)$ of the composite samples was calculated using Scherer's formula and is presented in Table 1. The data presented in the table are an average of ten readings. It can be observed from the table that the crystallite size of the composites is in the nano range and decreases with an increase in polymer content.

Figure 2 gives the SEM photographs of all nanocomposites. It can be seen from the figures that the nanocomposites exhibit a two-phase system with polymer grains (white) and NiZn ferrite grains (black). Energy-dispersive $\mathrm{X}$-ray spectroscopy (EDS, not given) was used to confirm the grains of these two phases. The connectivity of NiZn ferrite grains is dispersed by the distribution of polymer grains, which leads to the variation of magnetic properties of the composites. It can be observed from the images that the average grain sizes of the samples are in the range $50 \pm 1-80 \pm 1 \mathrm{~nm}$; the data reported in table are an average of twenty readings. The grain size of the composites is somewhat larger than the crystallite size calculated by the XRD method, which is due to the existence of the amorphous polymer matrix and the partial particle aggregation.

The theoretical density of the composites is calculated using the equation:

$\rho=m 1+m 2 / m 1 \rho 1+m 2 \rho 2+\rho 1 \rho 2$

where $m 1$ and $m 2$ are the masses of NiZn ferrite and polymer, respectively, and $\rho 1, \rho 2$ and $\rho$ the theoretical densities of NiZn ferrite, polymer and composites, respectively. The bulk density of the composites is measured by Archimedes principle and they are in the range of 95-96\% of the theoretical density. The bulk density of the nanocomposites are found to decrease (Table 1) with increasing polymer content, because NiZn ferrite and polymer can be densified by the interaction of the two phases that coexist in one material. The SEM pictures and appearance of the sintered samples show that no mismatch has occurred in the composites, which indicates that the two phases have better cofiring properties. Table 1 also gives values of lattice constant (a) for the composites. It can be seen from the table that the lattice constant was found to increase with an increase in the ferrite phase in the composite, because growth of the spinel lattice increases by the incorporation of polymer content. The average porosity in the present nanocomposites is $6 \%$.

The FTIR spectra for the nanocomposites are shown in the Fig. 3. It can be seen from the figure that an absorption peak is observed around $3,430 \mathrm{~cm}^{-1}$ due to the hydroxyl stretching vibration. The peak observed at $2,960 \mathrm{~cm}^{-1} \mathrm{can}$ be assigned to the $\mathrm{C}-\mathrm{H}$ stretching vibration. For the PFD, the characteristic peaks are located at 1,579, 1,494, 1,251, 1,133 and $800 \mathrm{~cm}^{-1}$. The peaks at 1,579 and $1,494 \mathrm{~cm}^{-1}$ are attributed to the characteristic $\mathrm{C}=\mathrm{C}$ stretching of the quinoid and benzenoid rings, the peaks at 1,300 and $1,251 \mathrm{~cm}^{-1}$ are assigned to $\mathrm{C}-\mathrm{N}$ stretching modes of the benzenoid ring and the broad and strong peak around $1,133 \mathrm{~cm}^{-1}$ as the "electronic-like band" was associated with vibrational modes of $\mathrm{N}=\mathrm{Q}=\mathrm{N}$ ( $\mathrm{Q}$ refers to the quinonic type rings), indicating that PFD is present in our samples. The peaks observed at $1,110 \mathrm{~cm}^{-1}$ are associated with the $\mathrm{C}-\mathrm{O}-\mathrm{C}$ symmetrical stretching vibration, and the peaks at 949 and $841 \mathrm{~cm}^{-1}$ correspond to the $\mathrm{C}-\mathrm{H}$ bending wagging vibration and the deformation vibration of $\mathrm{O}-\mathrm{C}-\mathrm{O}$ of $\mathrm{PFD}$ (Zhao et al. 1997). In addition, absorption peak observed at $609 \mathrm{~cm}^{-1}$ in the FTIR spectra of Ni-Zn ferrite is attributed to the intrinsic vibration of the tetrahedral and octahedral sites. According to the geometrical configuration of the oxygen nearest neighbors, the metal ions are usually situated in two different sub-lattices in ferrites, designated as the tetrahedral and octahedral sites. The vibration spectra 


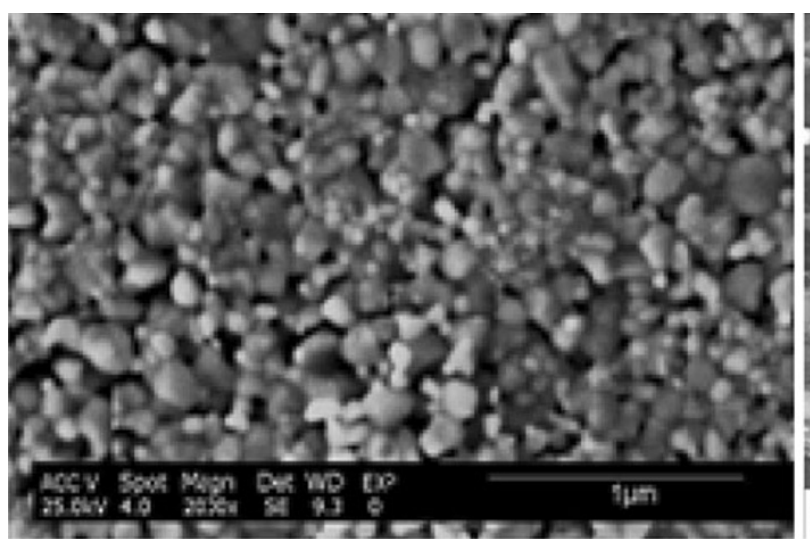

(a) $\mathrm{NZ1}$

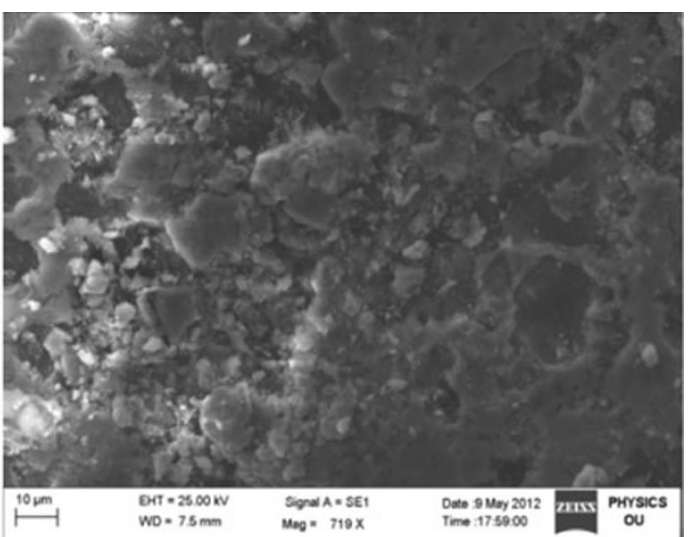

(bi) NZ2

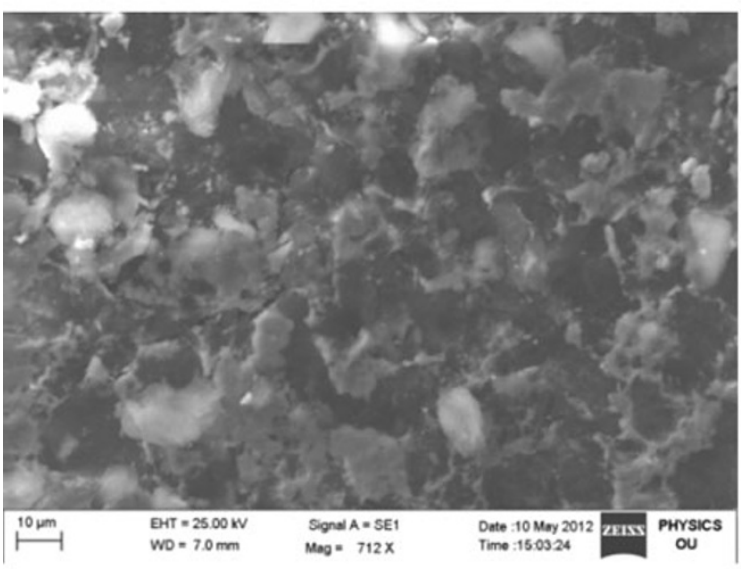

(bii) $\mathrm{NZ3}$

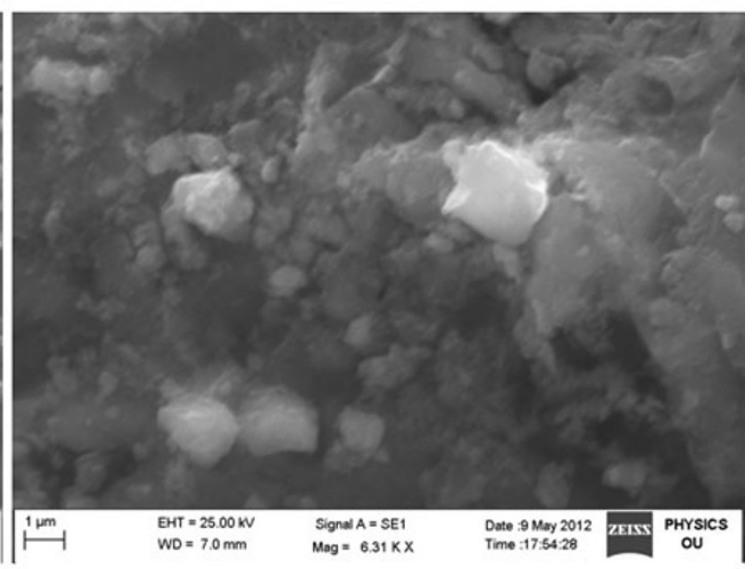

(biii) NZ4

Fig. 2 a TEM for NZ1, b SEM images of $x$ PZF $+(1-x)$ NZF nanocomposites $(0 \leq x \leq 1)$. (i) NZ 2, (ii) NZ 3 and (iii) NZ 4

Table 1 Room temperature experimental data for $x \mathrm{PZF}+(1-x) \mathrm{NZF}$ nanocomposites $(0 \leq x \leq 1)$

\begin{tabular}{llllllr}
\hline $\begin{array}{l}\text { Sample } \\
\text { name }\end{array}$ & $\begin{array}{l}\text { Crystallite size } \\
\text { from XRD }(\mathrm{nm})\end{array}$ & $\begin{array}{l}\text { Grain size from } \\
\text { SEM }(\mathrm{nm})\end{array}$ & $\begin{array}{l}\text { Density } \\
\left(\mathrm{g} / \mathrm{cm}^{3}\right)\end{array}$ & $\begin{array}{l}\text { Lattice } \\
\text { constant } \\
(\mathrm{a})(\AA)\end{array}$ & $\begin{array}{l}\text { Saturation } \\
\text { magnetization } \\
M_{\mathrm{s}}(\mathrm{emu} / \mathrm{g})\end{array}$ & $\begin{array}{l}\text { Coercivity } \\
H_{\mathrm{c}}(\mathrm{Oe})\end{array}$ \\
\hline NZ 1 & 37 & 35 & 5.313 & 8.408 & 63 & 9 \\
NZ 2 & 18.5 & 30 & 5.210 & 8.391 & 41 & 12 \\
NZ 3 & 15 & 20 & 5.129 & 8.384 & 30 & 18 \\
NZ 4 & 13 & 18 & 5.024 & 8.322 & 1.8 & 14 \\
\hline
\end{tabular}

of spinel ferrites at the high frequency band $v_{1}$ $\left(600-580 \mathrm{~cm}^{-1}\right)$ and the low-frequency band $v_{2}$ $\left(440-400 \mathrm{~cm}^{-1}\right)$ are attributed to the intrinsic vibration of the tetrahedral sites and the octahedral sites, respectively (Li et al. 2006). The characteristic peak of ferrite at around $580 \mathrm{~cm}^{-1}$ in the nanocomposites confirms the presence of ferrite particles in all samples. Therefore, the result indicate that the NiZn ferrite nanoparticles are well dispersed in the PFD matrix. The polymer peak intensity increases with the decrease in NiZn ferrite.

Figure 4 shows the magnetic hysteresis curves of the composites under applied magnetic field at room temperature. The magnetization of PFD $+\mathrm{NiZn}$ ferrite nanocomposites exhibited a clear hysteretic behavior, and the area within the hysteresis loops was increased with increase in the ferrite content. Table 1 gives the values of saturation magnetization $\left(M_{\mathrm{s}}\right)$ and coercivity $\left(H_{\mathrm{c}}\right)$ for the present composites. The pure ferrite shows the saturation magnetization $\left(M_{\mathrm{s}}\right)$ value of $63 \mathrm{emu} / \mathrm{g}$, whereas the magnetization of nanocomposites decreases with increase in the content of PFD. This is due to the diamagnetic contribution of PFD. In a ferrimagnetism, due to antiferromagnetic coupling, the magnetic moments of $\mathrm{A}$ and $\mathrm{B}$ sites are aligned anti-parallel and do not cancel each other, resulting 


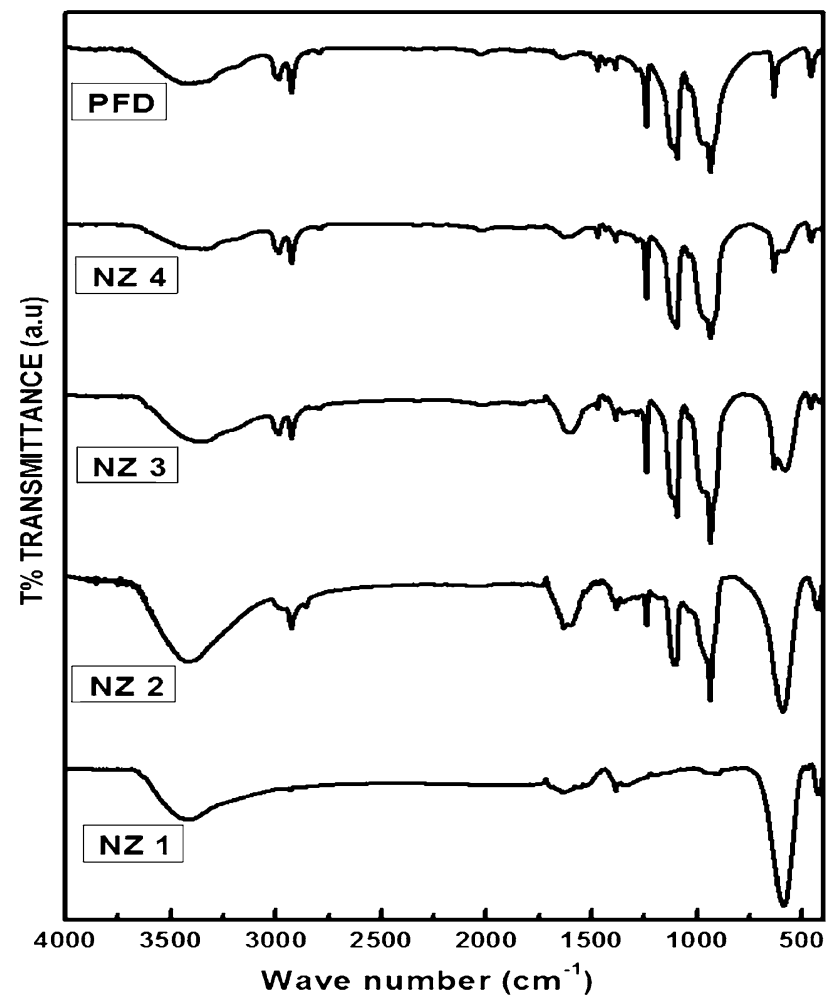

Fig. 3 FTIR spectra of synthesized $x$ PZF $+(1-x)$ NZF nanocomposites $(0 \leq x \leq 1)$

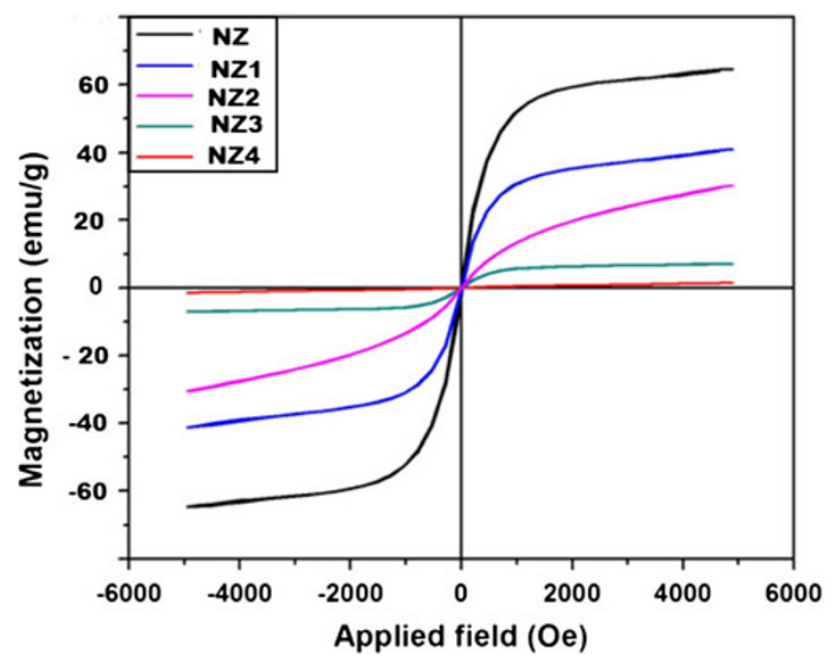

Fig. 4 VSM loops of $x \quad \mathrm{PZF}+(1-x)$ NZF $\quad(0 \leq x \leq 1)$ nanocomposites

in a net magnetization. The value of $M_{\mathrm{s}}$ depends on the total mass of the magnetic material. The reduction of $M_{\mathrm{s}}$ value may be caused by non-colinearity of the magnetic moments at the surface of the nanoparticles, resulting in a decrease in the saturation magnetization at higher polymer content. It is observed that the saturation magnetization of nanocomposites was increased with the ferrite content and was smaller than that of the pure ferrite, according to the

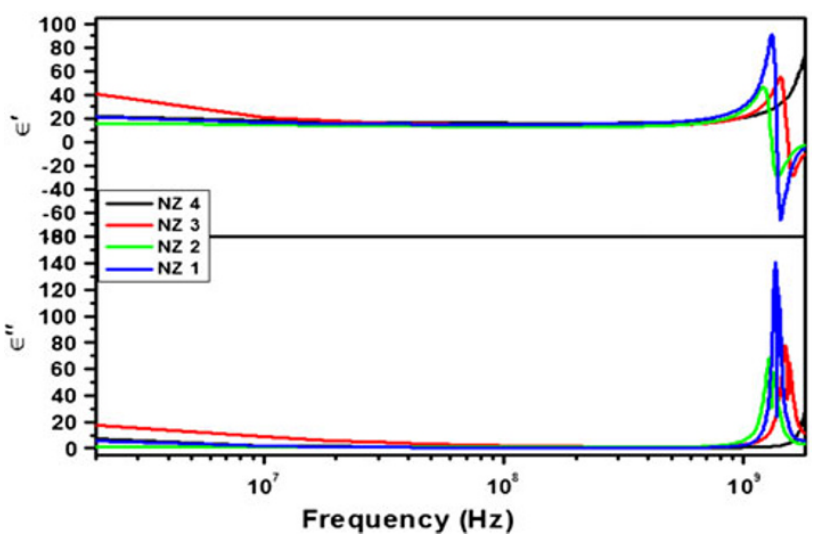

Fig. 5 Frequency dependence of real and imaginary parts of permittivity of $x \mathrm{PZF}+(1-x) \mathrm{NZF}(0 \leq x \leq 1)$ nanocomposites

equation $M_{\mathrm{s}}=V_{\mathrm{f}} m_{\mathrm{S}}$, where $V_{\mathrm{f}}$ is related to the volume fraction of the particles and $m_{\mathrm{S}}$ is related to the saturation moment of a single particle $\left(m_{\mathrm{S}}\right)$ (Chein 1995; Perepechko 1981). It may be considered that the saturation magnetization of the nanocomposites depends on the volume fraction of the magnetic ferrite particles, due to the diamagnetic PFD contribution to the total magnetization, resulting in the changes in saturation magnetization. The values of coercivity increase with ferrite content up to $x=0.75$ and then decrease. The decrease in coercivity is due to the fact that the higher ferrite content consists of a greater number of domain walls. The magnetization or demagnetization caused by domain wall movement requires less energy. As the number of walls increases with crystallite size, the contribution of wall movement to magnetization or demagnetization is greater than that of single-domain rotation (Perepechko 1981; Tareev 1975). Therefore, the samples with higher ferrite content are expected to have a lower coercivity.

Figure $5 \mathrm{a}, \mathrm{b}$ shows the variation of the real $\left(\varepsilon^{\prime}\right)$ and imaginary $\left(\varepsilon^{\prime \prime}\right)$ parts of permittivity with frequency at room temperature for all composites. It can be observed from the figure that the values of $\varepsilon^{\prime}$ and $\varepsilon^{\prime \prime}$, increase with increasing ferrite content in composites, but are lower than those of the pure ferrite (NZ 1). The lower values of $\varepsilon^{\prime}$ and $\varepsilon^{\prime \prime}$ of the composites can be attributed to the effect of dilution of the ferrites due to polymer, which have a dielectric permittivity between 2 and 4 . Thus, the real and imaginary parts of dielectric permittivity depend on the composition of the ferrite. Both the real and imaginary parts of permittivity for all the composites decrease as the frequency increases and are the normal behavior of ferrites. The high value of dielectric constant at low frequencies can be explained on the basis of space charge polarization, which is a result of the presence of higher conductivity phases (grains) in the insulating matrix (grain boundaries) of a dielectric causing localized accumulation of charge under the influence of an 
electric field. The decrease is rapid at lower frequencies and becomes slow at higher frequencies. The decrease takes place when the jumping frequency of electric charge carriers cannot follow the alteration of applied AC electric field beyond a certain critical frequency (Tareev 1975; Maxwell 1973) and remains constant over the entire frequency range. This suggests the presence of more $\mathrm{Fe}^{3+}$ ions rendering the ferrite structure highly homogeneous. The dielectric constant decreases with increasing polymer content; at the same time, the dielectric loss also decreases. The results may be due to polymer addition which suppressed the grain growth and caused the grain size to decrease, so that the proportion of the grain boundary was enhanced and this also contributed to the decrease of the dielectric constant (Maxwell 1973).

A large difference between the experimental data and the predicted data has been observed when the mixing rule $\epsilon_{\mathrm{C}}=\epsilon_{\mathrm{f}} V_{\mathrm{f}}+\epsilon_{\mathrm{P}} V \mathrm{p}$ (where $V_{\mathrm{f}}=$ fraction volume of ferrite, $V \mathrm{p}=$ fraction volume of polymer, $V_{\mathrm{f}}+V \mathrm{p}=1$ ) was used for the composite system. The difference may due to the porosity $(P)$ of the composite (Koops 1951) and the correction factor porosity $(P)$ was added to the mixing rule. The equation then becomes $\epsilon_{\mathrm{C}}=\epsilon_{\mathrm{f}} V_{\mathrm{f}}+\epsilon_{\mathrm{P}} V \mathrm{p}$ $(1-\mathrm{P})+P$. This rule was used at different frequencies and little difference was observed between experimental and theoretical values obtained by the mixing rule. Porosity phenomena cannot be considered because the observed discrepancy does not obey a constant value. At high frequencies, the interaction of ferrite-polymer in the applied electrical field is possible. The above equation can be modified by introducing an interaction factor: $C \mathrm{ij}$, then $\epsilon_{\mathrm{C}}=\epsilon_{\mathrm{f}} V_{\mathrm{f}}+\epsilon_{\mathrm{P}} V \mathrm{p}+C \mathrm{ij}$, where $C \mathrm{ij}$ is related to the applied frequency. A plot (not given)of $\epsilon^{\prime}$ versus the ferrite volume ratio in the composite with the ferrite composition

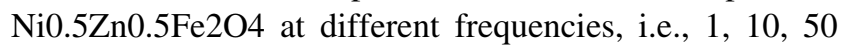
and $100 \mathrm{MHz}$ shows that $\epsilon^{\prime}$ remains constant with frequency. This behavior in the dielectric constant with frequency indicates that the resonant phenomenon is not present at these frequencies.

Figure 6 shows the real $\left(\mu^{\prime}\right)$ and imaginary $\left(\mu^{\prime \prime}\right)$ parts of permeability for composite samples at room temperature. It can be observed from the figure that the real $\left(\mu^{\prime}\right)$ part of permeability for NiZn ferrite remained almost constant, until the frequency was raised to a certain value and then began to decrease at higher frequency. The imaginary $\left(\mu^{\prime \prime}\right)$ part of permeability gradually decreased with an increase in frequency and took a maximum at a certain frequency, where the $\mu^{\prime}$ rapidly decreased. The experimental frequency $f_{\mathrm{c}}$ (resonance or relaxation), at which $\mu^{\prime \prime}$ has a maximum value, is about $80 \mathrm{MHz}$. It can be seen from the figure that composites show relaxation type of permeability dispersion. In composites, the values of $\mu^{\prime}$ become larger than those of the sintered ferrites, and also the critical

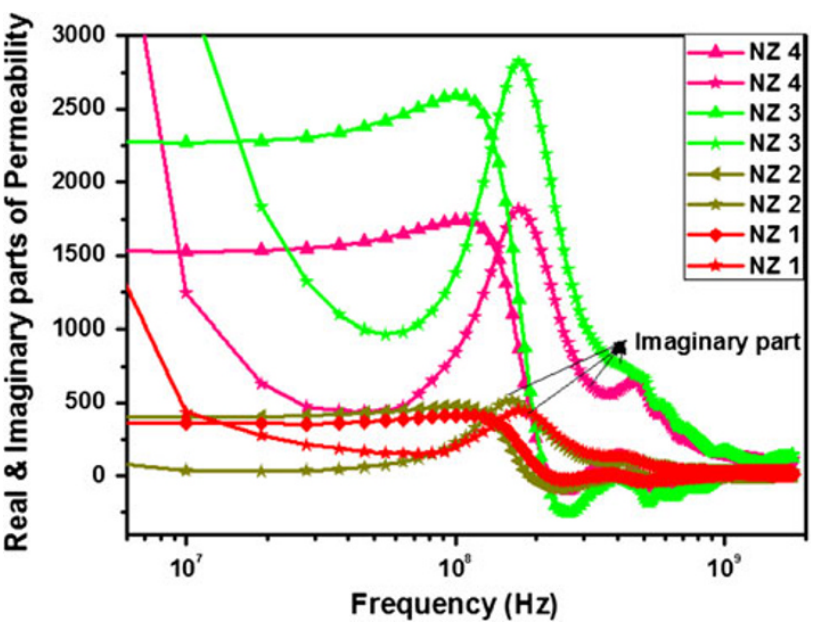

Fig. 6 Frequency dependence of real and imaginary parts of permeability of $x \mathrm{PZF}+(1-x) \mathrm{NZF}(0 \leq x \leq 1)$ nanocomposites

frequencies $f_{\mathrm{c}}$, at which $\mu^{\prime}$ has a maximum value are higher. In addition, the composites with higher content of polymer have larger values of $\mu^{\prime}$. For composites, the imaginary permeability changes continuously from NiZn ferrite to NiZn ferrite/polymer. Also, the critical frequencies $f \mathrm{c}$ change continuously and shift toward higher values with the increase in polymer fraction. Since the composite contains non-magnetic gaps, the demagnetizing field $H_{\mathrm{D}}$ is present along the circumference of the ring core. Hence, the $\mu^{\prime}$ value at low frequencies is reduced by the $H_{\mathrm{D}}$. On the other hand, the rotational frequency is related to the anisotropy field $H_{\mathrm{A}}$ antiparallel to the applied AC field and increases with $H_{\mathrm{D}}$ (Leslie-Pelecky and Rieke 1996). Thus, the value of $H_{\mathrm{A}}$ is also influenced by the change in NiZn ferrite fraction in the composite. The value of $\mu^{\prime}$ decreases and rotational frequency shifts higher due to the contribution of magnetocrystalline anisotropy field to the $H_{\mathrm{A}}$. As a result, the complex permeability spectra of composite samples NZ 3 and NZ 4 were decomposed into the domain wall (DW) and rotational components. Consequently, the complex permeability can be controlled continuously between the composite structures. These materials seem to be good candidates for applications such as EMI suppressors in portable and wireless electronic equipments.

\section{Conclusions}

A series of nanocomposites of nickel-zinc ferrite + paraformaldehyde was successfully synthesized using the mechanical milling process. The milling process significantly influences the crystallite size of nanocrystalline nickel-zinc ferrite in the composite. With the increase in the volume of polymer, the permittivity, permeability, and 
dielectric and magnetic loss of all the composites decreases. The permittivity and permeability of all the composites have shown good frequency stability and low dielectric and magnetic losses within the measurement range. Such magnetic composites are candidates for capacitor-inductor integrating devices such as electromagnetic interference filters in RF communications.

Acknowledgments The authors are thankful to UGC-BSR, New Delhi, India for providing funds and research fellowship for carrying out the present work.

Open Access This article is distributed under the terms of the Creative Commons Attribution License which permits any use, distribution, and reproduction in any medium, provided the original author(s) and the source are credited.

\section{References}

Ahmad N, MacDiarmid AG (1996) Inhibition of corrosion of steels with the exploitation of conducting polymers. Synth Met 78:103-110

Ambrose T, Gavrin A, Chien CL (1992) Magnetic properties of nanocomposite $\mathrm{Fe}-\mathrm{Al}_{2} \mathrm{O}_{3}$ using high energy ball-milling. J Magn Magn Mater 116:L311-L314

Chein CL (1995) Magnetism and Giant Magneto-Transport Properties in Granular Solids. Annu Rev Mater Sci 25:129-160

Costa ACFM, Tortella E, Morelli MR, Kiminani RHGA (2003) Synthesis, microstructure and magnetic properties of $\mathrm{Ni}-\mathrm{Zn}$ ferrites. J Magn Magn Mater 256:174-182

Da Silva JB, Mohallem NDS (2001) Preparation of composites of nickel ferrites dispersed in silica matrix. J Magn Magn Mater 226-230:1393-1396

Danielle C, Michelle S, Ivo A, Aldo Z (2003) Preparation and characterization of novel hybrid materials formed from $(\mathrm{Ti}, \mathrm{Sn})$ O2 nanoparticles and polyaniline. Chem Mater 15(24):4658-4665

Giri AK (1997) Magnetic properties of iron-polyethylene nanocomposites prepared by high energy ball milling. J Appl Phys 81:1348-1350

Giri AK, De Julian C, Gonzalez JM (1994) Coercivity of $\mathrm{Fe}-\mathrm{SiO}_{2}$ nanocomposite materials prepared by ball milling. J Appl Phys 76:6573-6575

Jalaly M, Enayati MH, Karimzadeh F (2009) Investigation of structural and magnetic properties of nanocrystalline $\mathrm{Ni}_{0.3} \mathrm{Zn}_{0.7}$ $\mathrm{Fe}_{2} \mathrm{O}_{4}$ prepared by high energy ball milling. J Alloys Compd 480:737-740

Kan JQ, Pan XH, Chen C (2004) Polyaniline-uricase biosensor prepared with template process. Biosens Bioelectron 19:1635-1640
Kazantseva NE, Vilčáková J, Křesálek V, Sáha P, Sapurina I, Stejskald J (2004) Magnetic behaviour of composites containing polyaniline-coated manganese-zinc ferrite. J Magn Magn Mater 269:30-37

Koops CG (1951) On the dispersion of resistivity and dielectric constant of some semiconductors at audio frequencies. Phys Rev $83: 121-124$

Kuwabata S, Masui S, Yoneyama H (1999) Charge-discharge properties of composites of LiMn2O4 and polypyrrole as positive electrode materials for $4 \mathrm{~V}$ class of rechargeable $\mathrm{Li}$ batteries. Electrochim Acta 44(8):4593-4600

Leslie-Pelecky DL, Rieke RD (1996) Magnetic properties of nanostructured materials. Chem Mater 8:1770-1783

Li L, Jiang J, Xu F (2006) Novel polyaniline- $\mathrm{LiNi}_{0.5} \mathrm{La}_{0.02} \mathrm{Fe}_{1.98} \mathrm{O}_{4}$ nanocomposites prepared via an in situ polymerization. Eur Polym J 42(10):2221-2227

Linderoth S, Pedersen MS (1994) $\mathrm{Fe}-\mathrm{Al}_{2} \mathrm{O}_{3}$ nanocomposites prepared by high-energy ball milling. J Appl Phys 75:5867-5869

Mäkelä T, Pienimaa S, Taka T, Jussila S, Isotalo H (1997) Thin polyaniline films in EMI shielding. Synth Met 85:1335-1336

Maxwell JC (1973) Electricity and magnetism. Oxford University Press, London

Perepechko II (1981) An introduction to polymer physics. Mir Publishers, Moscow

Qiu Y, Gao L (2005) Novel polyaniline/titanium nitride nanocomposite: controllable structures and electrical/electrochemical properties. J Phys Chem B 109(42):19732-19740

Sertkol M, Koseŏglu Y, Baykal A, Kavas H, Basaran AC (2009) Synthesis and magnetic characterization of $\mathrm{Zn}_{0.6} \mathrm{Ni}_{0.4} \mathrm{Fe}_{2} \mathrm{O}_{4}$ nanoparticles via a polyethylene glycol-assisted hydrothermal route. J Magn Magn Mater 321:157-162

Shull RD, Ritter JJ, Shapiro AJ, Swartzendruber LJ, Bennet LH (1990) Iron magnetic moments in iron/silica gel nanocomposites. J Appl Phys 67:4490-4492

Sohn BH, Cohen RE, Papaefthymiou GC (1998) Magnetic properties of iron oxide nanoclusters within microdomains of block copolymers. J Magn Magn Mater 182:216-224

Tareev B (1975) Physics of dielectric materials. MIR Publishers, Moscow

Yang QL, Zhai J, Feng L, Song YL, Wan MX, Jiang L, Xu WG, Li QS (2003) Synthesis and characterization of conducting polyaniline/ $\gamma-$ $\mathrm{Fe}_{2} \mathrm{O}_{3}$ magnetic nanocomposite. Synth Met 135-136:819-820

Yavuz Ö, Ram MK, Aldissi M, Poddar P, Hariharan S (2005) Synthesis and the physical properties of MnZn ferrite and NiMnZn ferrite-polyaniline nanocomposite particles. J Mater Chem 15:810-817

Zhao M, Zhou Y, Bruening ML, Bergbreiter DE, Crooks RM (1997) Inhibition of electrochemical reactions at gold surfaces by grafted, highly fluorinated, hyperbranched polymer films. Langmuir 13:1388-1391 